\title{
Effect of diclofenac on the pharmacokinetics of ciprofloxacin in quail
}

\author{
Y.Z. Alabdaly \\ Department of Physiology, Biochemistry and Pharmacology College of Veterinary Medicine, University of Mosul, Mosul, \\ Iraq
}

\begin{tabular}{l} 
Article information \\
\hline Article history: \\
Received September 22, 2020 \\
Accepted January 23, 2021 \\
Available online October 1, 2021 \\
\hline Keywords: \\
Pharmacokinetics \\
Ciprofloxacin \\
Diclofenac sodium \\
Spectrophotometer \\
Quail
\end{tabular}

Correspondence:

Y.Z. Alabdaly

yalabdali@yahoo.com

\begin{abstract}
This study investigated the Pharmacokinetics of ciprofloxacin alone or with diclofenac sodium in adult Japanese quails. The quails divided into two groups, the first group was dosed intraperitoneally with $50 \mathrm{mg} / \mathrm{kg}$ of ciprofloxacin, the second group was injected by $50 \mathrm{mg} / \mathrm{kg}$ of ciprofloxacin intraperitoneally then directly injected intraperitoneally by diclofenac sodium at a dosage of $5 \mathrm{mg} / \mathrm{kg}$. Plasma concentrations of ciprofloxacin were determined by the spectrophotometer at wavelength $290 \mathrm{~nm}$. Co-admiration of ciprofloxacin with diclofenac lead to appearing ciprofloxacin in plasma at 12.02, 6.4, 5.3, $3.30,1.36,0.60 \mu \mathrm{g} / \mathrm{ml}$ in the periods of $0.25,0.50,1,2,4$ and 8 hours post-injection. A significantly increased in the concentration of ciprofloxacin at times of $0.25,0.50,1$, and 2 hours post-injection and appeared at a concentration of $6.96,3.09,2.2$, and $0.72 \mu \mathrm{g} / \mathrm{ml}$. The pharmacokinetics of ciprofloxacin when given with diclofenac sodium was represented by $91 \%$ decrease in elimination constant rate, 53\% decrease in elimination half-life t1/2, 64\% decrease in volume of distribution to steady-state, $22 \%$ decrease in clearance, $28 \%$ increase area under curve, $41 \%$ decrease in area under moment curve, $53 \%$ decrease in mean residence time and 37\% increase in maximum plasma concentration. Our study concludes that co-administration of ciprofloxacin with diclofenac sodium lead to alteration in some pharmacokinetic data of ciprofloxacin like effect on the plasma concentration and volume of distribution and clearance. This effect must be considered when therapy by ciprofloxacin with diclofenac, the co-administration of diclofenac with ciprofloxacin decrease the elimination of ciprofloxacin.
\end{abstract}

DOI: 10.33899 /ijvs.2021.128440.1576, (CAuthors, 2021, College of Veterinary Medicine, University of Mosul.

This is an open access article under the CC BY 4.0 license (http://creativecommons.org/licenses/by/4.0/).

\section{Introduction}

Ciprofloxacin belongs to Fluoroquinolones its molecular formula is $\mathrm{C}_{17} \mathrm{H}_{18} \mathrm{FN}_{3} \mathrm{O}_{3}$, it's an antibiotic with a broad spectrum, the mechanism of its action is inhibiting DNA gyrase and a type II topoisomerasen (1). Diclofenac is a non-steroidal anti-inflammatory drug. The toxicokinetic in quail has belonged to metabolic capacity with $\mathrm{t}_{1 / 2}$ and mean residence time MRT above 8 hours with apparent signs of toxicities (2-4). Study of pharmacokinetics for enrofloxacin and ciprofloxacin in cow and steers showed the plasma elimination half-life for two drugs were longer in steers lactating cow than in cow (5). Bioavailability of ciprofloxacin when orally given is within a percentage of
$70-80 \%$, complete absorption of ciprofloxacin is generally not achieved following oral administration with no substantial loss by first-pass metabolism (6). Bioavailability of ciprofloxacin after oral administration is not altering by drug-food interactions although prolong the time required to reach maximum plasma concentration ( $\mathrm{t}$ max) and thus affect the area under the concentration-time curve (7). Because it is little binding to plasma proteins and good penetration in various fluids and tissues of the body. It has high distribution, except the central nervous system (CNS) $(8,9)$. Ciprofloxacin is different from other drugs in degree of metabolism and elimination in the liver or by renal excretion, that in the metabolism of ciprofloxacin decrease antimicrobial activity by glucuronide conjugation at the 3- 
carboxylic group. The piperazine ring increased metabolism, and these results reduced antimicrobial activity (10). Ciprofloxacin is excreted by kidney through glomerular filtration and renal tubular secretion, although elimination occurs by other routes like liver especially in case of renal impairment, in this case dose, adjustment is required for that case (8). In the study of pharmacokinetic data of ciprofloxacin and enrofloxacin for different animals species recorded no difference between the clearance and volume of distribution (11). In the comparative study between marbofloxacin and ciprofloxacin during the steady-state period, found the interstitial fluid and plasma-unbound concentrations were similar for two drugs despite differences in lipophilicity and pharmacokinetic parameters of the two drugs (12). Enrofloxacin is high lipophilicity and protein binding than marbofloxacin and ciprofloxacin (13).

To date, pharmacokinetic parameters have only been studied for ciprofloxacin and its interaction with another drug in pharmacological doses. Thus, we conducted to study the effect of diclofenac on the pharmacokinetics of high dose ciprofloxacin in quail.

\section{Materials and methods}

\begin{abstract}
Animals
Adult male Japanese quail weighing 200-290 gram, aged 40 days. Animals were raised in cages under uniform conditions in room temperature, water, and food in the animal house of the College of Veterinary Medicine, Mosul University.
\end{abstract}

\section{Drugs and chemicals used}

Pure ciprofloxacin hydrochloride powder and pure diclofenac sodium powder (drug nenava industry) were used. The original drug acetonitrile from TEDA Company, England. Ninety-six males of quail divided into two groups were used in the study; each group consists of 48 birds, which is randomly divided. The first group, treated intraperitoneally i.p by ciprofloxacin $50 \mathrm{mg} / \mathrm{kg}$ body weight, the second group treated by ciprofloxacin $50 \mathrm{mg} / \mathrm{kg}$ i.p and then directly injected by diclofenac sodium $5 \mathrm{mg} / \mathrm{kg}$ i.p (14). Blood sampling collected with anticoagulant heparin from TEDA Company by cutting jocular vein of each bird in the periods of $0.25,0.50,1,2,4$ and 8 hours (birds for each group). All blood samples were centrifuged at 3000 cycles/minute for $15 \mathrm{~min}$ and then the plasma was separated. The obtained plasma samples were stored at $-20^{\circ} \mathrm{C}$. The method depends on spectrophotometric ciprofloxacin estimation (15).

\section{Preparation of standard solutions}

A stock standard solution $1 \mathrm{mg} / \mathrm{ml}$ of ciprofloxacin hydrochloride. Working standard solutions 100,10 and 1 $\mu \mathrm{g} / \mathrm{mL}$ were prepared by serial dilution of the stock standard solution with distilled water. The standard solutions were protected from light and were used on the same day. Linear regression analysis of the calibration data was performed using the linear equation $\mathrm{y}=\mathrm{MX}+\mathrm{c}$ (Figure 1).

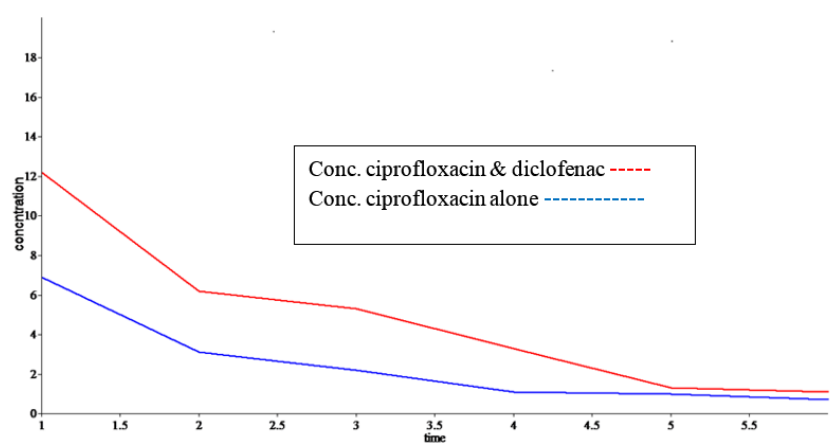

Figure 1: Semi-logarithmic plasma concentration-time profiles of concentration of ciprofloxacin in plasma of quail treated with and without diclofenac.

\section{Sample preparation}

Plasma blank in a 5-ml Eppendorf tubes, $2 \mathrm{~mL}$ of acetonitrile was added to $1 \mathrm{~mL}$ of plasma. The mixture was mixed up for $30 \mathrm{~s}$ with a mechanical shaker and centrifuged for $5 \mathrm{~min}$ at $10000 \mathrm{~g}$. A $2.5 \mathrm{ml}$ volume of clear supernatant was transferred into a qewvite to measure the ciprofloxacin plasma concentration by UV spectrophotometer at wave length $290 \mathrm{~nm}$. The data of ciprofloxacin concentration was used for the Pharmacokinetic analysis program.

\section{Pharmacokinetic analysis}

The analysis was carried out using specialized software non-compartmental Windows-based computer program (16). The parameter was elimination constant rate $(\mathrm{k})$, Elimination half-life t1 / 2, the volume of distribution to steady-state (Vss), Clearance, the area under curve AUC 0-, AUMC, MRT, and maximum plasma concentration (C $\max )$.

\section{Static analysis}

Result analysis by two-way analysis of variance then result was applied to least significant difference by SPSS program of the level of significant $\mathrm{P}<0.05$.

\section{Results}

\section{Pharmacokinetic data}

Plasma concentration of single dose of ciprofloxacin 50 $\mathrm{mg} / \mathrm{kg}$ i.p, when co-administered with diclofenac $5 \mathrm{mg} / \mathrm{kg}$ i.p were 12.0, 6.4, 5.3, 3.3, 1.3 and $1.1 \mu \mathrm{g} / \mathrm{kg}$ after time of $0.25,0.50,1,2,4$ and 8 hour (Table 1). While ciprofloxacin plasma concentration when treated animals with single dose of ciprofloxacin $50 \mathrm{mg} / \mathrm{kg}$ i.p., were 6.9, 3.09, 2.2, 1.07, 1.14 , and 0.71 after time of $0.25,0.50,1,2,4$ and 8 hour. 
Table 1: Plasma concentration of ciprofloxacin in animals treated with and without diclofenac

\begin{tabular}{lcccccc}
\hline \multirow{2}{*}{ Groups } & \multicolumn{5}{c}{ Time /hour } \\
\cline { 2 - 7 } & 0.25 & 0.50 & 1 & 2 & 4 & 8 \\
\hline Ciprofloxacin $50 \mathrm{mg} / \mathrm{kg}$ & $6.9 \pm 0.4$ & $3.1 \pm 0.2$ & $2.2 \pm 0.05$ & $1.1 \pm 0.1$ & $1.0 \pm 0.08$ & $0.7 \pm 0.1$ \\
Ciprofloxacin $50 \mathrm{mg} / \mathrm{kg}+$ diclofenac $5 \mathrm{mg} / \mathrm{kg}$ & $* 12.2 \pm 0.5$ & $* 6.4 \pm 0.3$ & $* 5.3 \pm 0.5$ & $* 3.3 \pm 0.2$ & $1.3 \pm 0.3$ & $1.1 \pm 0.4$ \\
\hline
\end{tabular}

The value represents group of 6 animals. *value is significantly different from group of Ciprofloxacin $50 \mathrm{mg} / \mathrm{kg}$.

This result reflected on pharmacokinetic parameters for group of ciprofloxacin with diclofenac by Elimination constant rate $(\mathrm{k})=0.69 \mathrm{hr}-1$, Elimination half-life $\mathrm{t} 1 / 2=$ $4.25 \mathrm{hr}$., Volume of distribution to steady state (Vss) $=10.63 \mathrm{~L} / \mathrm{kg}$, Clearance $=2.01 \mathrm{~L} / \mathrm{h} / \mathrm{kg}$, area under concentration extrapolated to time infinity $=24.88 \mu \mathrm{g} / \mathrm{hr} /$ $\mathrm{ml}$., area under moment concentration AUMC $=131.5 \mu \mathrm{g} /$ $\mathrm{hr}-1 / \mathrm{ml}$, Mean Resident Time MRT $=5.22 \mathrm{hr}$., and highest plasma concentration (C) $12.2 \mu \mathrm{g} / \mathrm{ml}$ (Table 2). The changes in pharmacokinetic data when comparing between the two groups of ciprofloxacin with and without diclofenac sodium were represented as percentage of $91 \%$ decrease in elimination constant rate $(\mathrm{k}), 53 \%$ decrease in elimination half-life t1 / 2, 64\% decrease in volume of distribution to steady-state (Vss), 22\% decrease in clearance, $28 \%$ increase area under curve AUC 0-, $41 \%$ decrease in AUMC, 53\% decrease in MRT and $37 \%$ increase in maximum plasma concentration (Table 2).

Table 2: Pharmacokinetic parameters of ciprofloxacin in animals treated with diclofenac and without it

\begin{tabular}{lccc}
\hline Pharmacokinetic parameters & $\begin{array}{c}\text { Ciprofloxacin } \\
50 \mathrm{mg} / \mathrm{kg}\end{array}$ & $\begin{array}{c}\text { Ciprofloxacin50mg/kg } \\
\text { with diclofenac } 5 \mathrm{mg} / \mathrm{kg}\end{array}$ & $\begin{array}{c}\text { \%changes from two } \\
\text { groups }\end{array}$ \\
\hline CL L/h/kg Clearance & 2.57 & 2.01 & $22 \% \downarrow$ \\
MRT hr Mean residence time & 11.38 & 5.29 & $53 \% \downarrow$ \\
Vss L/kg Volumes of Distribution & 29.21 & 10.63 & $64 \% \downarrow$ \\
Terminal K- Elimination constant rate & 7.7 & 0.69 & $91 \% \downarrow$ \\
Terminal t1 $12 \mathrm{hr}$. & 8.97 & 4.25 & $53 \% \downarrow$ \\
T max hr. Maximum time & 1.00 & 1.00 & 0 \\
C max $\mu$ g/mL Maximum concentration & 6.96 & 12.02 & $73 \% \uparrow$ \\
AUC extrapolated to time infinity $\mu \mathrm{g} . \mathrm{h} / \mathrm{mL}$ & 19.48 & 24.88 & $28 \% \uparrow$ \\
Presented extrapolated AUC $\mu \mathrm{gg} . \mathrm{h} / \mathrm{mL}$ & 47.03 & 24.05 & $49 \% \downarrow$ \\
AUMC Area Under Moment Curve & 221.74 & 131.58 & $41 \% \downarrow$ \\
Percent extrapolated AUMC & 38.51 & 27.50 & $29 \% \downarrow$ \\
\hline
\end{tabular}

\section{Discussion}

There are different aspects of drug interaction at the pharmacokinetics and pharmacodynamics levels (17). In the present study, the pharmacokinetic parameters following intravenous administration of ciprofloxacin in quail were very similar to those reported previously conducted in humans and animals (18-21). but there is no study on this type of interaction in quail birds, therefore we have conducted this study. However, the pharmacokinetic analysis showed that the concomitant administration of diclofenac and ciprofloxacin decreased in ciprofloxacin clearance that agreement with (22). That effect may back to increasing renal tubular reabsorption and reduced renal clearance that maybe belong to alkaline in $\mathrm{pH}$ number for the ciprofloxacin and diclofenac sodium that causes competition between ciprofloxacin and diclofenac that result consistent with the study (23) that showed NSAIDs can cause drug-drug interactions specially in excretion. Also (18) recorded that oral co-administration of ciprofloxacin with diclofenac elevated ciprofloxacin AUC and Cmax, and decreased ciprofloxacin tmax and total body clearance, in addition to affect the intrinsic hepatic clearance.

The decrease in $\mathrm{Vd}$ and body clearance may have been due to a decrease in intrinsic hepatic clearance and blood flow or a decrease in renal clearance, as has been observed with co-administration of intravenous ciprofloxacin with orally administered probenecid (21). Increased bioavailability of ciprofloxacin has also been reported with co-administration of ciprofloxacin with probenecid. Similar modifications in ciprofloxacin pharmacokinetic characteristics augmented AUC and Cmax and body clearance were also reported with phenazone coadministered by dogs (18).

Significant modifications in important pharmacokinetic parameters of ciprofloxacin noted when diclofenac is administered simultaneously indicates that diclofenac can modify ciprofloxacin absorption / metabolism / elimination. Ciprofloxacin has also decreased overall clearing of the body. These findings suggest that as a result of concomitant diclofenac administration the tissues distribution of the drug 
are significantly decreased volume of distribution are lead to increase concentration in the blood coupled with a decrease in drug concentration in tissue $(24,25)$. We need more studies to detect the effect of drug interaction with other non-steroidal anti-inflammatory drugs on another aspect.

\section{Conclusions}

The key results of this study are that the bioavailability of ciprofloxacin increases with the administration of diclofenac and co-management must be taken with further precautions.

\section{Acknowledgement}

The study was supported by College of Veterinary Medicine, University of Mosul.

\section{Conflict of interest}

There is no conflict of interest.

\section{Reference}

1. Vyas A, Purohit A, Ram H. Assessment of dose-dependent reproductive toxicity of diclofenac sodium in male rats. Drug Chem Toxicol. 2019;42(5):478-86. DOI: 10.1080/01480545.2017.1421659

2. Akter R, Sarker M. Effect of diclofenac sodium in broilers. Bangladesh J Vet Med. 2015;13(1):19-24. DOI: 10.3329/bjvm.v13i1.23710

3. Naidoo V, Duncan N, Bekker L. Validating the domestic fowl as a model to investigate the pathophysiology of diclofenac in Gyps vultures. Environ Toxicol Pharmacol. 2007;24(3):260-266. DOI: 10.1016/j.etap.2007.06.003

4. Reddy NP, Anjaneyulu Y, Sivasankari B, Rao KA. Comparative toxicity studies in birds using nimesulide and diclofenac sodium. Environ Toxicol Pharmacol. 2006;22(2):142-7. DOI: 10.1016/j.etap.2006.02.004

5. Rao GS, Ramesh S, Ahmad AH, Tripathi HC, Sharma LD, Malik JK. Pharmacokinetics of enrofloxacin and its metabolite ciprofloxacin in goats given enrofloxacin alone and in combination with probenecid. Vet J. 2002;163(1):85-93. DOI: 10.1053/tvj1.2001.0594

6. Lauardi M, Hermanto B, Restiadi T. Assessment of the withdrawal period for ractopamine hydrochloride in the goat and sheep. Iraqi $\mathbf{J}$ Vet Sci. 2020;34(2):405-410. DOI: 10.33899/ijvs.2019.126114.1237

7. Cheng D, Xu WR, Liu CX. Relationship of quantitative structure and pharmacokinetics in fluoroquinolone antibacterials. World J Gastroenterol. 2007;13(17):2496. DOI: 10.3748/wjg.v13.i17.2496

8. Başaran A, Erol K, Başaran N, Güneș HV, Acikalin E, Timuralp G, Değirmenci I, Çakmak EA, Tomatir AG. Effects of ciprofloxacin on chromosomes, and hepatic and renal functions in rats. Chemother. 1993;39(3):182-8. DOI: 10.1159/000239124

9. Xiao C, Han Y, Liu Y, Zhang J. Relationship between fluoroquinolone structure and neurotoxicity revealed by zebrafish neurobehavior. Chem Res Toxicol. 2018;31(4):238-250. DOI: 10.1021/acs.chemrestox.7b00300

10. Metwally NH, Mohamed MS. Pyrazoloquinazoline derivatives: Synthesis, reactions, and biological applications. Synth Commun. 2018;48(7):721-46. DOI: 10.1080/00397911.2017.1399208

11. Yet L. Privileged structures in drug discovery. Hoboken: John Wiley and Sons; 2018. 356-413 p.
12. Kang J, Hossain MA, Park HC, Kim Y, Lee KJ, Park SW. Pharmacokinetic and pharmacodynamic integration of enrofloxacin against Salmonella enteritidis after administering to broiler chicken by per-oral and intravenous routes. J Vet Sci. 2019;20(2)1-10. DOI: 10.4142/jvs.2019.20.e15

13. Alabdaly YZ, Saeed MG, Al-hashemi HM. Effect of methotrexate and aspirin interaction and its relationship to oxidative stress in rats. Iraqi $\mathrm{J}$ Vet Sci. 2021;35(1):151-156. DOI: 10.33899/ijvs.2020.126490.1335

14. Ocampo HL, Tapia G, Mendoza C. Pharmacokinetics of enrofloxacin $\mathrm{HCl}-2 \mathrm{H} 2 \mathrm{O}$ (Enro-C) in dogs and pharmacokinetic/pharmacodynamic Monte Carlo simulations against Leptospira spp. J Vet Sci. 2018;19(5):600-607. DOI: 10.4142/jvs.2018.19.5.600

15. Hussain I, Khan MZ, Khan A. Toxicological effects of diclofenac in four avian species. Avian Pathol. 2008;37(3):315-321. DOI: 10.1080/03079450802056439

16. Patel SA, Patel NM, Patel MM. Simultaneous spectrophotometric estimation of ciprofloxacin and ornidazole in tablets. Indian $\mathrm{J}$ Pharmaceut Sci. 2006;68(5):1-4. DOI: 10.4103/0250-474x.29645

17. Laub PB, Gallo JM. NCOMP: A windows-based computer program for noncompartmental analysis of pharmacokinetic data. J Pharmaceut Sci. 1996;85(4):393-395. DOI: 10.1021/js9503744

18. Abdullah RA, Taee FD, Thanoon I A. Effect of levofloxacin on some body tissues in mice. Iraqi J Vet Sci. 2021;35(1):109-111 DOI: 10.33899/ijvs.2020.126416.1316

19. Iqbal Z, Khan A, Naz A, Khan JA, Khan, G.S. Pharmacokinetic interaction of ciprofloxacin with diclofenac. Clin Drug Investigat. 2009;29(4):275-281. DOI: 10.2165/00044011-200929040-00006

20. Keizer RJ, Huitema $\mathrm{AD}$, Schellens JH, Beijnen JH. Clinical pharmacokinetics of therapeutic monoclonal antibodies. Clin Pharmaco. 2010;49(8):493-507. DOI: 10.2165/11531280-00000000000000

21. Hagenbuch B. Drug uptake systems in liver and kidney: a historic perspective. Clin Pharmacol Therapeut. 2010;87(1):39-47. DOI: 10.1038/clpt.2009.235

22. Jaehde U, Sörgel F, Reiter A, Sigl G, Naber KG, Schunack W. Effect of probenecid on the distribution and elimination of ciprofloxacin in humans. Clin Pharmacol Therapeut. 1995;58(5):532-41. DOI: 10.1016/0009-9236(95)90173-6

23. Cooke CE, Sklar GE, Nappi JM. Possible pharmacokinetic interaction with quinidine: Ciprofloxacin or metronidazole?. Ann Pharmacother. 1996;30(4):364-366. DOI: $10.1177 / 106002809603000408$

24. Brouwers JR, de Smet PA. Pharmacokinetic-pharmacodynamic drug interactions with nonsteroidal anti-inflammatory drugs. Clin Pharmacokinet. 1994;27(6):462-485. DOI: 10.2165/00003088199427060-00005

25. Saleh YZ. Toxic effect of ciprofloxacin on some biochemical variables in chicks. Iraqi J Vet Sci. 2010;24:141-137. DOI: www.doi.org/10.33899/ijvs.2010.5603

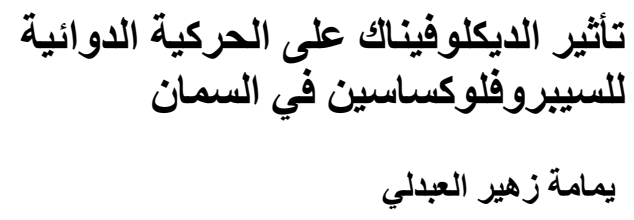

فرع الفسلجة و الكيمياء الحياتية و الأدوية، كلية الطب البيطري، جامعة الموصل، الموصل، العراق أنسات

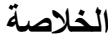

بحثت هذه الدراسة الحركية الدوائية للسيبروفلوكساسين لوحده أو أو الوابئ

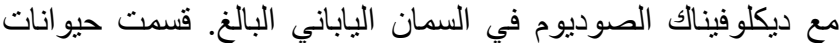






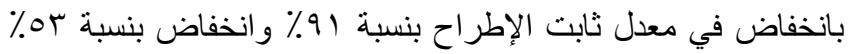

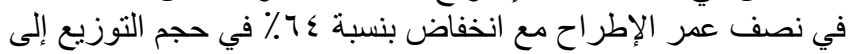

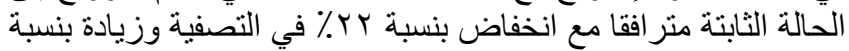

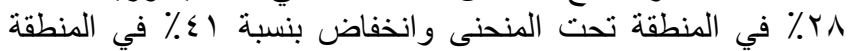

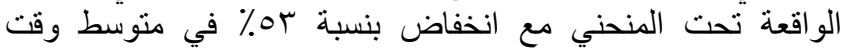

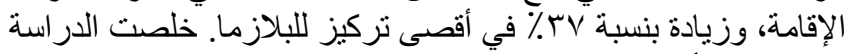

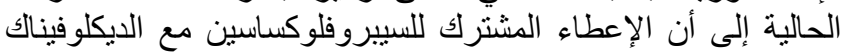

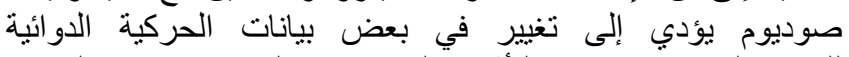

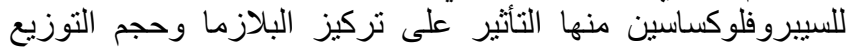

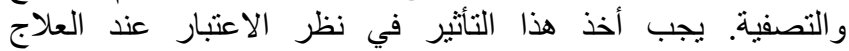
بالسيبروفلوكساسين مع الديكلوفينالك.
• 0 مجم / كجم من سيبروفلوكساسين. أما المجموعة الثانية فحقتت

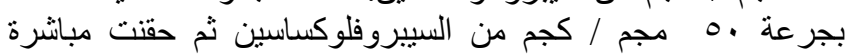

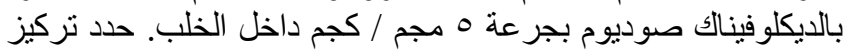

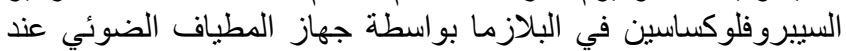

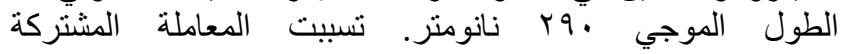

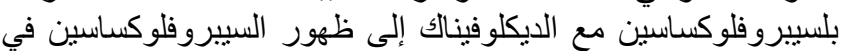

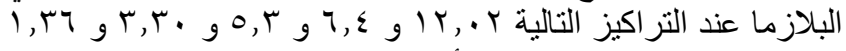

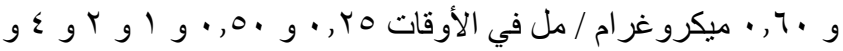



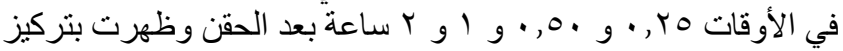

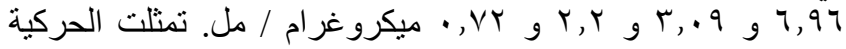

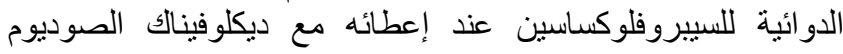

